before operation, to order that the seat of injury be treated for a week or 10 days with radiant-heat baths, from $150^{\circ}$ to $250^{\circ} \mathrm{F}$. for 10 minutes daily. If incarcerated sepsis is present the scar in the course of two or three days becomes inflamed ; finally, fluctuation occurs and, as a rule, a small quantity of pus is evacuated. The wound is then encouraged to heal, and after healing, in a period of time varying from two weeks to three months, according to the severity of the secondary manifestation of sepsis, a further course of radiant heat is ordered. If no reartion occurs within a week the operation may be safely proceeded with so far as any danger of buried sepsis is concerned. In no case of mine in which this preliminary treatment has been carried out has there been failure with a rigid aseptic technique. The chief point I wish to make is that the wounds have, after this course, pursued a healthy manner of healing and no further infection has taken place. A smaller advantage of radiant-heat treatment is that the scars become more healthy and thinner, more mobile, and more elastic.

Lance-Corporal - G.S.W. of left forearm on Oct. 24tb, 1916, admitted into Northumberland War Hospital, Nov. lst. On admission: Great swelling of forearm, with two wounds. One longitudinal about $3 \frac{1}{2}$ inches long on lower part of flexor aspect with gaping edges and $3 \frac{1}{2}$ inches long on lower part of flexor aspect with gaping edges and
exposing torn muscle. A rubber drain passed from this through arm to second wound about 2 inches long on extensor aspect of forearm. to second wound about 2 inches long on extensor aspect of forearm. Both wounds were actively septic, covered with grey unhealthy lvmph
and discharging pus ; surrounding skin red, shiny, and tense. The end and discharging pus; surrounding skin red, shing, and tense. The end of a comminuted fractured ulna protruded through posterior wound ;
radius also fractured. Cultures taken by Dr. Clark showed $B$. perradius also fractured. Cultures taken by
fringens, $B$. coli, staphylococel, streptococci.

fringens, $B$. coli, staphylococci, streptococci.
Treatment.-Oct. 25th: Under C.I. wound was scraped out gently with sharp spoon, washed with 1-20 carbolic, packed with magnes, sulph. cream, and dressed with sterilised gauze and cotton-wool. Rectangula internal splint applied. Nov. 3rd: Patient complained of pain in arm. T. $101^{\circ} 6^{\circ}$. Considerable brawny swelling of arm extending above elbow skin red and inflamed, and the bacteriologist reported anaerobic organisms present. Under $C$. E. vertical incisions were made into cellular tissue of upper arm, and these were washed out with magnesium hypochlorite and peroxide of hydrogen and dressed with mag. sulph. oream. Wounds in forearm looked clean and less swollen.

Nov. 8th: Secondary hæmorrhage from wound. Wound opened up and attempt made to secure bleeding points. As this could not be satisfactorily accomplished brachial artery was tied above bend of elbow and wound packed with gauze and dressed with Bipp. Nov. 15th : Dressed. Packing removed; very little discharge; no hamorrhage; wound looked clean and bealthy. Dressed with mag. sulph. cream. Nov. 24th: Dressed. Good deal of watery discharge on dressings; wound clean and covered with granulations. Bridge of skin between two wounds looked like sloughing. Dec. 1st : Dressed. Wound closing in ; small piece of bone removed.

Feb. 16th, 1917: Wound healed. March 23rd : Movements much Feb, 16th, 1917: Wound healed. March 23rd : Movements much
improved, X rays show gap of over 2 inches in middle of ulna; several improved. X rays show gap of over 2 inches in middle of ulna; several loose pieces of bone; no displacement. Sent to convalescent home. June 1st: Returned from convalescent home. Wounds sonndly appeared in scar and burst this morning. June 15 th : Wound healed. appeared in scar and burst this

July 14th : Returned from convalescent home. Rariant heat commenced. July 28th: No reaction to radiant heat. Operation. Scar over ulna exeised. Graft about 3 inches long taken from tibia and implanted into gap in ulna. August 4th: Dressed. Wound healed. August 11th : Dressed. Arm put up in plaster. Sent to convalescent home for two munths.

The method is simple and the results so satisfactory that I venture to suggest the adoption of radiant-heat treatment as a routine method of preparation, more especially in nerve and bone surgery, where the results of sepsis are likely to be disastrons.

I have to thank Colonel G. G. Adams, administrator, Northumberland War Hospital, Gosforth, Newcastle-on-Tyne, tor permission to publish these cases.

Sunderland.

\section{IMPRESSIONS OF $\mathrm{X}$ RAY TREATMENT. ${ }^{1}$}

BY W. G. HARVEY, M.D. DUB., F.R.C.P. IREL.,

TEMP. MA.TOR, R.A.M.C. ; ASSISTANT PHYSICIAN AND IN CHARGE OF X RAY DEPARTMENT, ADELAIDE HOSPITAL, DUBLIN, ETC.

THE object of this note is to give an estimate of the value of Roentgen therapy in various conditions, derived from an experience of over 500 cases. The conditions dealt with were:-

1. Ringworm -in this the rays are used as an epilating agent. A fortnight after a proper dose of $X$ rays the irradiated area sheds all its hair, healthy and parasitic, while some three months later a new growth of hair, free from the parasite, occurs. This treatment is the best for the cure of ringworm ; it is certain, painless, and rapid, leaving the

Thead before the Section of Medicine of the Royal Aeademy of Medicine in Ireland.
Mead before the child free from infection within a month of starting. There are, however, many technical points which require attention, or accidents-e.g., alopecia-may occur.

2. The results in favus theoretically should be equally good, but such cases often become reinfected.

3. Rodent ulcers in general do well, unless the periosteum or cartilage be involved. True epitheliomata are more variable, but many respond well to $\mathrm{X}$ rays.

4. Epithelioma on a lupus site should never be treated with $X$ rays - the results are very bad.

5. Warts-senile and juvenile-are amenable to $\mathrm{X}$ ray treatment. Four cases of warty growths on the feet did well.

6. Keloid is satisfactory in its response to $X$ rays.

7. Lupus does well, but the cosmetic results of Finsen light are probably better. Tuberculin injections appear to favour the treatment.

8. Lupus erythematosus is not benefited.

9. The results with tuberculous glands have not been all that was to be desired.

10. Actinomycosis (one case) was not affected. In the treatment of neoplasms and deep-lying tissues much improvement has been obtained since the methods of "filtration" and "cross fire" were introduced.

11. The symptoms of Graves's disease subsided under $\mathbf{X}$ rays. No considerable benefit was derived in simple goitre.

12. Malignant tumours, whenever possible, should be surgically removed. When that is impossible $X$ rays may occasionally bring about a cure, and frequently will relieve pain and diminish the tumour.

13. Uterine myomata and enlarged prostates require massive doses of $\mathbf{X}$ rays, but with such appear to do well.

\section{Clintial 影otes:}

MEDICAL, SURGICAL, OBSTETRICAL, AND THERAPEUTICAL.

\section{A CASE OF SUCCESSIVE GASTRO-JEJUNAL} PERFORATIONS.

By W. H. C. Romanis, M.C.Cantab., F.R.C.S.ENG.

THE following case of successive perforations of gastric and jejunal ulcers is of-interest not only on account of th number of occasions on which the patient perforated and recovered, but also because of the length of time during which she remained free from tronble, followed later by recrudescence of symptoms and further perforation.

The patient, an unmarried woman of 37 , was first admitted to St. Thomas's Hospital on March 25th, 1903, with all the symptoms of perforated gastric ulcer; operation was performed by Mr. W. H. Battie and a perforated pyloric ulcer was sutured. She then remained quite well until the following October, when vomiting and gastric pains commenced, and in April, 1904, Mr. Battle performed an anterior gastro-enterostomy for pyloric stenosis. This was followed by a period
of good health until May 5th, 1905, when she was readmitted to of good health until May 5th, 1905, when she was readmitted to was performed and a perforated jejunal ulcer 1 inches below the gastrowas performed and a perforated jejunal ulcer 18 inches below the gastroenterostomy anastomosis was found and sutured; the patient made an uninterrupted recovery and 10 months' complete health followed. On March 14th, 1906, after a fortnight's epigastric discomfort, she was suddenly seized with severe pain and admitted to St. Thomas's, stating that she had perforated again. Mr. Battle again opened the abdomen and found and sutured a round perforation

After this all went well for 11 years, and the patient was in excellent health till June 9th, 1917, when, after three weeks" "indigestion," "she again presented herself at the hospital, declaring that she had perforated six hours before! That this had indeed occurred there was no possible doubt, and the writer was requested by Mr. Battle to deal with the case. Laparotomy (for the fifth time) disclosed an abdomen practically free from adhesions but full of fluid. No signs of the previous pyloric ulcer were present, the old anastomosis was patent and in good order, but in the jejunum inch below there was a large round perforation surrounded by a small indurated area. This was easily elosed with two continuous catgut sutures and covered over with an omental grafi ; the abdomen was mopped dry with gauze and closed without drainage. The patient made a rapid recovery, and when last seen was well and remained quite free from pain.

Many cases of jejunal ulcer following the operation of gastro-enterostomy-especially anterior gastro-enterostomy -have now been recorded, but it is well known that they apparently occur almost exclusively after operations for non-malignant disease of the stomach. A considerable number of such ulcers have perforated, but it is not many 
patients who have been unfortunate enough to suffer from four successive perforations. The first three perforations in the above patient have been referred to by Mr. Battle in his work on "The Acute Abdomen," and it was through his courtesy that I was enabled to deal with so remarkable a case and at his request that these notes are now published.

\section{A CASE OF GUNSHOT WOUND OF THE HEAD.}

By WinifRed BuCKLEY, M.R.C.S.,

SLRGEON TO THE MLLITARY HOSPITAL, ENDELL-STREET, LONDON.

I venture to publish the following case as being one of general interest.

Private, aged 24, wounded in France early in October, was transferred to Military Hospital, Endell-street, on ninth day after injury. Statement on field medical oard to the effect that he was suffering from "penetrating wound of sealp above and behind left ear, was much

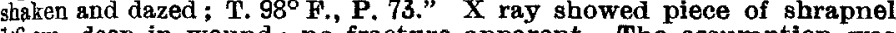
$16 \mathrm{~cm}$. deep in wound; no fracture apparent. The assumption was that foreign body was lying superficial to skull.

The morning after admission patient very drowsy, but conscious; T. $98^{\circ}$, P. 60 . Pupils equal and reacting well. Discs showed some blurring of upper margin. There was no paralysis. The wound was slight and cicatrised. During the night he was very restless, and next day (eleventh from date of wounding) his condition became worse. By 4 P.M. he was deeply unconscious, very restless, and irritable; he had incontinence of fæces and urine, and fits started at 5 P.M. A. 5.30 anesthetic givert and $X$ ray taken; no fracture visible in plate.

He was taken to theatre, and on dissecting back the scalp flap I found a small punctured depressed fracture of parietal bone, with foreign body lying in it. I trephined over fracture, and on removing the bone an offensive odour was noticed and a quantity of septic bloodstained fluid escaped under pressure. The dura mater was torn and surface of brain bruised. A crucial incision of dura mater about 1 in. long was made; brain surface was irrigated with saline and some bruised tissue removed It was then treated with spirit and B IP P brused tap was closed with four fishine out sutures. 48 hours. The fuid contained streptot sutures; glove drain left in 48 hours. The fluid contained streptococci and Bacillus perfringens. The following morning patient was conscious and complained of headache. Temperature was raised for two nights and then became swelling developed under flap on twelfth day after operation. This hernia subsided and disappeared a fortaight later. His mental condition hernia subsided and disappear

The ophthalmic surgeon observed increased blurring of both dises a few days after operation, and patient suffered from double vision for seven weels. At the end of this time, he had headache and dizziness on walking. The double vision was less marked for distant than for near vision. In looking at near objects he saw two lines-the upper clear and horizontal; the lower starting at the same point but running obliquely down at about an angle of $30^{\circ}$.

His present condition is as follows. The wound is quite healed. He still suffers frequently from headaches. Sight good; no double vision now except when he looks down (extremely), and then it is only very slight. The ophthalmic surgeon reports that on rough testing the margins of the discs are clear and the right outer field of vision is absent. General health is good; intelligence unimpaired.

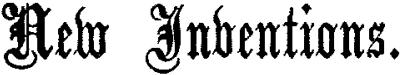

\section{AN AMPUTATION SHIELD RETRACTOR}

As is shown by the illustration, this retractor consists of two dish-shaped metal wings, which can be separated at the joint, passed over the stump flaps, and locked by a ratchet

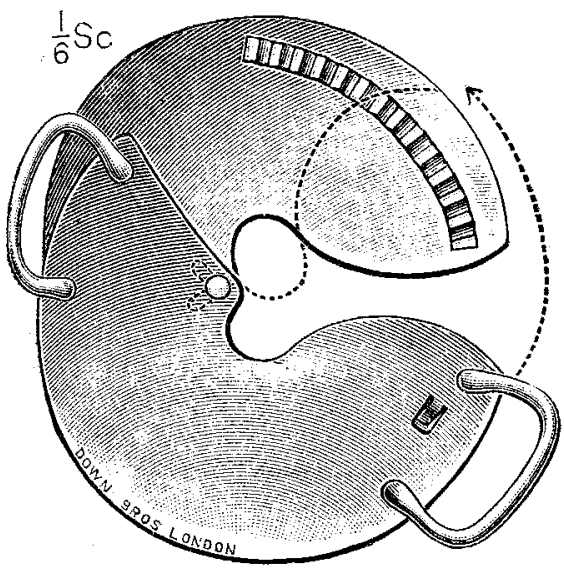
into a firm circular shield, on which traction is made by a pair of handles. I have used it now for over a year with satisfaction, a nd claim for it the following advantages: It is lighter than the average shield, it will go into the standard army steriliser, there are no parts that offer difficulty in cleaning, and it adjusts itself to the size of the bone and can be applied with the least amount of manipulation. The apparatus is made by Messrs. Down Bros., Limited, St. Thomas's-street, London, S.E.

VALENTINE H. Blake, M.B., B.S. Lond., Captain, R.A.M.C.

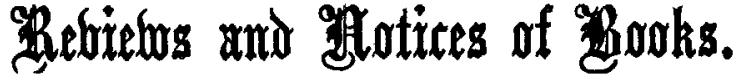

Glanooma. A Text-book for the Student of Ophthalmology. By Robert Henry Elliot, Lieutenant-Colonel, I.M.S. (retired). London: H. K. Lewis and Co. 1918. Pp. 546. Price 21s.

Lieutenant-Colonel Elliot has produced a monograph on glaucoma notable for clearness and fair-mindedness, and it should find a place in the library of every ophthalmic surgeon. It depicts all aspects of the disease and does justice to the work that has gone before as well as to that accomplished by contemporaries.

Colonel Elliot insists throughout on precision in terms, the meaning of which he carefully defines. He holds that the glaucomatous process is all one, and that although we speak of acute, subacute, and chronic stages of glaucoma, those terms should not be employed as though they implied different diseases. The subject of intra-ocular pressure is handled in an informing way, and it is pointed out that in dealing with the physical conditions which govern the behaviour of the intra-ocular fluid as it passes into and out of the eye we have to do with a body of moving water, so that the laws are those of hydrodynamics and not of hydrostatics, as has been maintained. Systemic blood pressure and intra-ocular pressure are related, but the relationship may be masked or even neutralised by other factors and the important conclusion is reached that the high blood pressure of general arterio-sclerosis is "emphatically not a factor in the causation of glaucoma." The author holds that in most cases glaucoma is readily recognised. The expression "prodromata of glancoma" is condemned, since he believes that an eye presenting such symptoms is detinitely glaucomatous.

The sections dealing with the visual fields in glancoma are among the best on the subject that we have ever read. Perimetry with large and small objects is discussed, and so is the anatomical distribution of the nerve-fibre bundles in its bearing on glaucomatous defects of the field. Great attention is paid to nasal contraction of the field to Roenne's nasal step, to Bjerrum's sign, and to Seidel's scotoma. The author has devised a new type of perimeter (described in the appendix to the book), and by its aid has hit upon a novel sign of glaucoma, which, with considerable modesty, he speaks of as " a development of Seidel's sign," and which may well prove of considerable clinical value. Seidel's sign, it may be recalled, which is found in cases of early glaucoma, takes the form of wing-like extensions from the blind spot. Colonel Elliot has found that the paracentral scotoma does not end, as described by Seidel, in a single point, but in a number of points both above and below, thus representing lesions to a number of nerve bundles at the edge of the optic disc. To put the matter in another way, Seidel depicted the sign as resembling a crescent moon, while Colonel Elliot likens it to a spread-out painter's brush. The difference between the two observers may probably be explained by the fact that on his new perimeter Colonel Elliot works at intervals of 1 degree, which Seidel apparently did not.

In speaking of the medical treatment of glaucoma de Wecker's striking words are quoted: "If miotics have never cured a case of glaucoma, they have prevented many glaucomatous patients from being cured." Colonel Elliot believes that the moment non-operative means show failure to hold the disease in check surgical measures should be adopted. Iridectomy is fully described -its history, the period at which it may be undertaken, and its techniqueand Oolonel Elliot concludes that it should be done only in early cases, where there is reason for thinking that it may succeed in freeing the natural channels for the escape of the aqueous humour from the eye. The object of the newer operations is of set purpose to produce a so-called " filtering cicatrix" (a phrase coined by de Wecker), and Colonel Elliot candidly says that "not one has yet been received as the last word in the surgical treatment." Those operations, such as Holth's, which aim at involving the iris in the wound, are condemned by the author. Sclerotomy has failed to afford the satisfaction that it seemed to promise. A filtering cicatrix was first deliberately obtained by Lagrange in 1906 . Other operations aiming at a similar result are those which bear 